\title{
Maternal Obesity And Pregnancy Outcome of 300 Obese Women In Coimbatore Medical College
}

\author{
Dr Teresa Karpaga Selvi $\mathrm{Md}^{1,}$ Dr N Kurinjipriya $\mathrm{Md}^{2}$ \\ ${ }^{1}$ Assistant Surgeon Department Of Obstetrics And Gynecology Coimbatore Medical College \\ Coimbatore,Tamilnadu. \\ ${ }^{2}$ Assistant Professor Department Of Obstetrics \&Gynaecology Coimbatore Medical College Hospital \\ Coimbatore, Tamilnadu.
}

\begin{abstract}
To examine the maternal and fetal risks of adverse pregnancy outcome in relation to maternal obesity, expressed as body mass index (BMI, $\mathrm{kg} \square \mathrm{m}^{2}$ ). The studyis aprospective cohort study. A comparison of pregnancy outcomes was made on the basis of maternal BMI at booking. 300 women with obesity BMI more than $24.99 \mathrm{~kg} / \mathrm{m}^{2}$ in obese groupis compared with 300 women with normal BMI 18.5 to $24.99 \mathrm{Kg} / \mathrm{m}^{2}$ in control group for a period of one year. The mean age of control group is 23.75 and for the obese group are 26.53.In age group above 30 years, obese women are $15.3 \%$ and normal weight women are $2 \%$. Whereas the control group had more primi gravida (53.7\%), there were more multigravida women $(58.9 \%)$ in the study group. $84.3 \%$ of obese women were in the Class I obesity with 10.7 and 5\% in Class II and III obesity respectively.In obese group GDM (14\%) of that 9\% of the GDM were on meal plan, 5\% on Insulin ,PIH is $74.3 \%$ of which $60.3 \%$ ( mild PIH) and $14 \%($ severe PIH),6.3\% are anemic, Placental abruption 3\%. In obese $21 \%$ had vaginal delivery,34\% emergency caesarean delivery,36\% emergency repeat caesarean delivery.Elective caesarean delivery in obese women was performed for $4.6 \%$ as primary section and $7 \%$ as repeat section.Instrumental delivery with forceps was $3 \%$ of women in obese group. Whereas $8.7 \%$ of women had CS due to delay in progression of labor, no such indication was noted in the non obese women. Third stage complications noted in obese group were PPH (2\%) and retained placenta (1\%).The NICU admission in control group is $10 \%$ and in obese group is $34.6 \%$. To conclude there is lot of complication in obesity complicating pregnancy in antenatal, intrapartum, postnatal period. There is increased risk for both mother and baby.
\end{abstract}

\section{Introduction}

Obesity has become a major health problem all over the world in endemic proportion .Now a days obesity affects all the age groups in both men and women. Obesity related diseases such as diabetes mellitus; hypertension, heart disease, stroke, and arthritis ultimately decrease the life span of the individual.

Obesity in female population has major impact on pregnancy. The rate of obesity in pregnant women is rising and consequently obesity related problems.The pregnancy complication associated with maternal obesity are divided in to two groups,

1. Affects primarily the mother.

2. Affects primarily fetus, newborn or the developing fetus.

Aims And Objectives

To evaluate the influence of obesity on pregnancy and to assess the adverse effects of its outcome in pregnancy.

\section{Materials And Methods}

Study Design: Prospective cohort study.

Study Place: Coimbatore Medical College

Study Period: July 2015 to June 2016

The study was approved by the Institutional Review Board (Ethical Committee).

After getting consent, detailed history was elicited and the mothers were examined in detail. The selected women were divided into 2 groups based on their BMI.

GROUP A (Control Group): 300 women with normal BMI 18.5 to $24.99 \mathrm{Kg} / \mathrm{m}^{2}$.

GROUP B (Study Group): 300 women with obesity BMI more than $24.99 \mathrm{~kg} / \mathrm{m} 2$.

\section{Inclusion Criteria}

1. Pregnant women with prepregnancy BMI $\geq 30 \mathrm{~kg} / \mathrm{m}^{2}$, prepregnancy BMI between $18.5 \mathrm{~kg} / \mathrm{m}^{2}$ and $24.99 \mathrm{~kg} / \mathrm{m}^{2}$.

2. Similar socioeconomic status.

3. Matched dietary habits. 


\section{Exclusion Criteria}

1.Women not booked at $\mathrm{CMCH}$ and whose prepregnancy BMI not known.

2.Women whose BMI $<18.5 \mathrm{~kg} / \mathrm{m}^{2}$ and BMI between $25 \mathrm{~kg} / \mathrm{m}^{2}$ and $29.9 \mathrm{~kg} / \mathrm{m}^{2}$

3.Women who are obese already with medical complication like diabetes, hypertension and hypothyroidism.

4. Women who could not be followed until delivery.

\begin{tabular}{|l|c|}
\hline I $\quad$ 1. Symphysio fundal height & V. Induction or acceleration of labour \\
2. Abdominal circumference & VI. Type of delivery 1. Labour natural \\
II. Increase or decrease in maternal & 2. Instrumental vaginal delivery \\
weight & 3. Cesarean section \\
III. Complication during antenatal period & VII. Complication during labour \\
$\begin{array}{l}\text { 1.Gestational Diabetes } \\
\text { 2.Anemia }\end{array}$ & 1. Delay in progress of labour \\
$\begin{array}{l}\text { 3.Preeclampsia } \\
\text { 4.Antepartum hemorrhage }\end{array}$ & 2. Incoordinate uterine contraction \\
& 3. Prolonged second stage of labour \\
& VIII. Third stage complication \\
& 1.Postpartum hemorrhageRetained Placenta \\
& IX. Fetal Complications \\
& 1. Macrosomia \\
& 2. NICU admission \\
& 3. Stillbirth \\
\hline
\end{tabular}

Age Distribution
\begin{tabular}{|l|c|c|c|c|}
\hline \multirow{2}{*}{ AGE GROUP } & \multicolumn{2}{|c|}{ CONTROL } & \multicolumn{2}{c|}{ OBESE } \\
\cline { 2 - 5 } & NO & $\%$ WITHIN GROUP & NO & $\%$ WITHIN GROUP \\
\hline$<20$ YEARS & 48 & $16 \%$ & 15 & $5 \%$ \\
\hline 21 to 25 YEARS & 164 & $54.7 \%$ & 114 & $38 \%$ \\
\hline 26 to 30 YEARS & 82 & $27.3 \%$ & 125 & $41.7 \%$ \\
\hline$>30$ YEARS & 6 & $2 \%$ & 46 & $15.3 \%$ \\
\hline
\end{tabular}

Table:-1 shows the age distribution in control and obese groups. 54.7\% of control group were in 21 to 25 years and $41.8 \%$ of obese group were in 26 to 30 years $p$ value $<0.001$

\begin{tabular}{|l|c|c|c|c|}
\multicolumn{4}{|c|}{ Parity } & \multicolumn{2}{c|}{ OBESE } \\
\hline \multirow{2}{*}{ PARITY } & \multicolumn{2}{|c|}{ CONTROL } & \multicolumn{2}{c|}{} \\
\cline { 2 - 5 } & NO & $\%$ WITHIN GROUP & NO & $\%$ WITHIN GROUP \\
\hline \multirow{2}{*}{ PRIMI } & 161 & $53.7 \%$ & 117 & $39 \%$ \\
\hline G2 AND G3 & 127 & $42.3 \%$ & 158 & $52.7 \%$ \\
\hline \multirow{2}{*}{ G4 AND ABOVE } & 12 & $4 \%$ & 25 & $8.3 \%$ \\
\hline
\end{tabular}

Table:-2shows the distribution of cases in gravida in control and obese group. The percentage of primi in control group is $53.7 \%$ and obese group is $39 \%$ but multi in this group is about $61 \%$ and the p value $<0.001$

Obese Women In Obesity Classification

\begin{tabular}{|l|c|c|}
\hline ASSIFICATION OF OBESE WOMEN & NO OF OBESE & \% WITHIN GROUP \\
\hline CLASS I (30-34.99kg/m2) & 253 & $84.3 \%$ \\
\hline CLASS II (35-39.99kg/m2) & 32 & $10.7 \%$ \\
\hline CLASS III (>=40.00 kg/m2) & 15 & $5 \%$ \\
\hline
\end{tabular}


Table:-3shows the percentage of obese cases in obesity classification. In 300 obese women about 253 were in class I group, 32 in class II and 15 in class III.

Gestational Diabetes

\begin{tabular}{|l|c|l|c|c|}
\hline \multirow{2}{*}{$\begin{array}{l}\text { GESTATIONAL } \\
\text { DIABETES }\end{array}$} & \multicolumn{2}{|c|}{ CONTROL } & \multicolumn{2}{c|}{ OBESE } \\
\cline { 2 - 5 } & NO & $\%$ WITHIN GROUP & NO & $\%$ WITHIN GROUP \\
\hline ON INSULIN & 0 & $0 \%$ & 27 & $9 \%$ \\
\hline ONMEALPLAN & 9 & $3 \%$ & 15 & $5 \%$ \\
\hline
\end{tabular}

Table:-4shows the incidence of gestational diabetes in control and obese group. In obese group GDM on in insulin is $9 \%$ and on mealplan is $5 \%$ with $\mathrm{p}$ value $<0.001$

Pregnancy Induced Hypertension

\begin{tabular}{|l|c|c|c|c|}
\hline \multirow{2}{*}{ PIH } & \multicolumn{2}{|c|}{ CONTROL } & \multicolumn{2}{c|}{ OBESE } \\
\cline { 2 - 5 } & NO & $\%$ WITHIN GROUP & NO & \%ITHIN GROUP \\
\hline \multirow{2}{*}{ MILD } & 26 & $8.7 \%$ & 181 & $60.3 \%$ \\
\hline SEVERE & 0 & $0 \%$ & 42 & $14 \%$ \\
\hline
\end{tabular}

Table:-5shows the incidence of PIH in control and obese group. In control group about $8.7 \%$ were mild PIH and in obese $60.3 \%$ were mild PIH and $14 \%$ were severe PIH with p value $<0.001$.

\section{Placental Abruption}

\begin{tabular}{|l|c|c|}
\hline ABRUPTIO PLACENTA & CONTROL & OBESE \\
\hline NO OF CASES & 0 & 9 \\
\hline$\%$ WITHIN GROUP & $0 \%$ & $3 \%$ \\
\hline
\end{tabular}

Table:-6shows the incidence of abruption placenta in control and obese group. 3\% of women in obese group had placental abruption

Anemia

\begin{tabular}{|c|c|c|}
\hline ANEMIA & CONTROL & OBESE \\
\hline NO OF CASES & 7 & 19 \\
\hline$\%$ WITHIN GROUP & $2.3 \%$ & $6.3 \%$ \\
\hline
\end{tabular}

TABLE:-7shows about $2.3 \%$ anemic cases in control and $6.3 \%$ cases in obese group

Induction Of Labour

\begin{tabular}{|l|c|c|c|c|}
\hline \multirow{2}{*}{ INDUCTION OF LABOUR } & \multicolumn{2}{|c|}{ CONTROL } & \multicolumn{2}{|c|}{ OBESE } \\
\cline { 2 - 5 } & NO & $\%$ WITHIN GROUP & NO & $\%$ WITHIN GROUP \\
\hline PGE $_{2}$ GEL INDUCTION & 24 & $8 \%$ & 27 & $9 \%$ \\
\hline OXYTOCIN INDUCTION & 0 & 0 & 27 & $9 \%$ \\
\hline OXYTOCIN ACCELERATION & 128 & $42.7 \%$ & 57 & $19 \%$ \\
\hline
\end{tabular}


TABLE:-8 shows the incidence of induction of labour in control and obese group. There is an increased number of induction in obese groupcompared to control group with $\mathrm{p}<0.001$

Type Of Delivery

\begin{tabular}{|l|c|c|c|c|}
\hline \multirow{2}{*}{ TYPE OF DELIVERY } & \multicolumn{2}{|c|}{ CONTROL } & \multicolumn{2}{c|}{ OBESE } \\
\cline { 2 - 5 } & NO & $\begin{array}{l}\% \text { WITHII } \\
\text { GROUP }\end{array}$ & NO & $\begin{array}{l}\% \text { WITHII } \\
\text { GROUP }\end{array}$ \\
\hline LABOUR NATURAL & 240 & $80 \%$ & 63 & $21 \%$ \\
\hline EMERGENCY LSCS & 44 & $14.7 \%$ & 102 & $34 \%$ \\
\hline EMERGENCY REPEAT LSCS & 14 & $4.7 \%$ & 108 & $36 \%$ \\
\hline ELECTIVE LSCS & 0 & $0 \%$ & 6 & $2 \%$ \\
\hline ELECTIVE REPEAT LSCS & 0 & $0 \%$ & 12 & $4 \%$ \\
\hline INSTRUMENTAL DELIVERY & 2 & $0.7 \%$ & 9 & $3 \%$ \\
\hline
\end{tabular}

Table:-9 shows the incidence of type of delivery in control and obese women.in control group about $80 \%$ of cases had labour natural and inobesegroup $76 \%$ had caesarean delivery and with the p value $<0.001$

Type Of Delivery In Obese Women

\begin{tabular}{|l|c|l|l|c|}
\hline \multirow{2}{*}{ OBESE WOMEN } & \multicolumn{2}{|c|}{ PRIMI } & \multicolumn{2}{c|}{ MULTI } \\
\cline { 2 - 5 } & NO & $\%$ WITHIN GROUP & NO & WITHIN GROUP \\
\hline LABOUR NATURAL & 15 & $11.6 \%$ & 48 & $27 . \%$ \\
\hline EMERGENCY LSCS & 102 & $79 \%$ & 108 & $63.1 \%$ \\
\hline ELECTIVE LSCS & 6 & $4.6 \%$ & 12 & $7 \%$ \\
\hline INSTRUMENTAL DELIVERY & 6 & $4.6 \%$ & 3 & $1.75 \%$ \\
\hline
\end{tabular}

Table:-10 shows the incidence of deliveries in primi and multigravida of obese group, $80.9 \%$ of obese primi had caesarean delivery compared to $62 \%$ in obese multigravida.

Delay In Progress

\begin{tabular}{|l|c|c|}
\hline DELAY IN PROGRESS & CONTROL & OBESE \\
\hline NUMBER OF CASES & 0 & 26 \\
\hline \% WITHIN GROUP & $0 \%$ & $8.7 \%$ \\
\hline
\end{tabular}

Table:-11 shows the incidence of delay in progress in control and obese group. $8.7 \%$ cases in obese group had delay in progress.

Third Stage Complication

\begin{tabular}{|l|c|c|}
\hline THIRD STAGE COMPLICATION & NUMBER OF CASES & \% WITHIN GROUP \\
\hline POSTPARTUM HAEMORRHAGE(PPH) & 6 & $2 \%$ \\
\hline RETAINED PLACENTA & 3 & $1 \%$ \\
\hline
\end{tabular}

Table:-12 shows $2 \%$ of obese women had PPH and $1 \%$ retained placenta 
Baby Weight

\begin{tabular}{|c|c|c|}
\hline BABY WEIGHT & CONTROL & OBESE \\
\hline MEAN WEIGHT & $2.82 \mathrm{Kg}$ & $3.47 \mathrm{Kg}$ \\
\hline
\end{tabular}

Table:-13shows the mean baby weight of control and obese group were $2.82 \mathrm{~kg}$ and $3.47 \mathrm{~kg}$ respectively

Nicu Admission

\begin{tabular}{|c|c|c|l|l|}
\hline \multirow{2}{*}{ NICU ADMISSION } & \multicolumn{2}{|c|}{ CONTROL } & \multicolumn{2}{c|}{ OBESE } \\
\cline { 2 - 5 } & NO & $\%$ WITHIN GROUP & NO & $\%$ WITHIN GROUP \\
\hline YES & 30 & $10 \%$ & 104 & $34.6 \%$ \\
\hline NO & 270 & $0 \%$ & 196 & $65.3 \%$ \\
\hline
\end{tabular}

Table:-14shows the incidence of NICU admission in control and obese group.

\section{Discussion}

The age group distribution in this study shows that percentage of normal weight women are more in 21 25 years of age $(54.7 \%)$ whereas percentage of obese women are more in the 26-30 years of age $(41.7 \%)$. In women above $30 \mathrm{yrs}$ of age, there is increased number of obese women (15.3\%), when compared to only $2 \%$ of normal weight women. The incidence of obesity increases with increase in age.

The incidence of obesity increases with parity. In the normal weight group, $53.7 \%$ were primi and $42.3 \%$ were multiparous. Whereas in the obese group only $39 \%$ women were primipara and $52.7 \%$ were multiparous. In grand multiparous women, $4 \%$ were normal weight and $6.2 \%$ were obese and p value is $<0.001$. Multiparous are more prone for obesity than primi.

The present study revealed a higher prevalence of GDM in obese women. Whereas $9 \%$ and $5 \%$ of obese women were on insulin and meal plan for the management of GDM, only $3 \%$ of women with normal weight were on meal plan with the $\mathrm{p}$ value is $<0.001$.There were no women on Insulin in the normal weight group. This is in concurrence with the study of Weiss and associates (FASTER Trial, 2004) which showed a marked increase in gestational hypertension and diabetes of class I (10.2\% \& $12.3 \%)$ and class II (6.3\% \& 9.5\%). In general 1-3\% of all pregnancies are diagnosed as gestational diabetes, while obese women have approximately $17 \%$ according to Gabeeetal. Pregnancy induced hypertension in antenatal period is higher in obese women (mild PIH of $60.3 \%$ and severe PIH of 14\%), when compared to normal weight women with mild PIH of $8.7 \%$ with the $\mathrm{p}$ value $<0.001$. O'Brien and associates (2003) reported that preeclampsia risk doubles with each $5-7 \mathrm{~kg} / \mathrm{m}^{2}$ increase in prepregnancy BMI. Similarly Seibare et al (2001) reported a 2 - 4 fold increase in preeclampsia in obese women. Kumari et al (2001) reported that preeclampsia in obese women was increased. Most of the women, about 89\%, with obesity proceeded to term gestation and preterm labor was noted in only $11 \%$. In normal weight women $98.7 \%$ were term gestation and $1.3 \%$ is preterm with the $\mathrm{p}$ value $<0.001$. This is in concurrence with the study of Cnattingius et al who reported an increased risk of delivery before 32 weeks in nulliparous obese women versus lean women. Similar findings for preterm delivery were reported by Baeten et al.The incidence of induction of labor was more in obese women due to indications like preeclampsia, gestational diabetes and fear of stillbirth in advanced gestation. The labor was induced with $\mathrm{PGE}_{2}$ gel in $9 \%$ and with oxytocin in $9 \%$. In those women with normal weight, $\mathrm{PGE}_{2}$ gel induction was $8 \%$ but oxytocin induction was $42.7 \%$ with the p value $<0.001$.This also correlates well with the study of Sebire et al (2001) who reported an increased rates of labor induction in obese women. But in another study Bianco et al (1998) reported the rate of oxytocin augmentation was similar in both the groups.

In the type of delivery, labor natural was about $80 \%$ in normal weight women compared to only $21 \%$ in obese women. The emergency caesarean delivery was $14.7 \%$ in normal weight women and $34 \%$ in obese women. The emergency repeat caesarean delivery rates were $36 \%$ in obese women and $4.7 \%$ in normal women. In the obese group, the labor natural in primi gravida was $11.6 \%$ and $27 \%$ in the multigravida, emergency caesarean delivery in primigravida was $79 \%$ and $63.1 \%$ in multigravida. Elective caesarean section in obese women for primi was $4.6 \%$ and repeat section was $7 \%$ and Instrumental delivery for primigravida was $4.6 \%$ and for multigravida was $1.75 \%$. Obese women have increased emergency caesarean delivery, compared to the normal weight women because of the macrosomia. This study shows there is a significant rise of caesarean delivery with obese women with the $\mathrm{p}<0.001$. Our study is in accordance with the study of Hugh M.Ehrenberg (2004) who reported a higher chance of cesarean delivery in obese women $(13.8 \%$ versus $7.7 \%, \mathrm{P}<0.0001)$. Lynch and associates (2008), Poobalan and colleagues (2009) also found that obese women have increased rate of cesarean 
delivery. Sebire (2001) and Baeten et al (2001) and Bianco et al (1n 1998) reported increased cesarean rate in obese women of more than $30 \%$.

The most common indication for cesarean delivery was previous cesarean delivery in both in normal and obese women, whose percentages are $24 \%$ and 52.6 respectively. In the indication for primary section of obese women cephalo pelvic disproportion stands first and it is $17.5 \%$. In the normal weight women fetal distress was the most common indication with an incidence of $32.7 \%$. Failed induction is one of the reasons for caesarean delivery in obese women and it is about $5.2 \%$. Severe preeclampsia is an indication in $3.4 \%$ of normal weight women compared to $10.5 \%$ of obese women. Whereas $2.6 \%$ and $1.3 \%$ of cesarean deliveries in obese women were due to malpresentation like breech and transverse lie respectively, $8.6 \%$ and $1.7 \%$ of the same was noted in normal weight women. The labour was prolonged in $8.7 \%$ of obese women. Third stage complications were more in the obese women, with PPH (2\%), and Retained placenta(1\%). Sebire et al (2001) also reported a higher incidence of PPH.

The mean birth weight in normal weight women was $2.82 \mathrm{~kg}$ and in obese women it was $3.47 \mathrm{~kg}$. Hugh M.Ehrenberg et al (2004) opined that obese women were at a higher risk of delivering large for gestational age babies (LGA) compared to women with normal weight( $16.8 \%$ vs. $10.5 \%$;) The NICU admission were increased in obese women about $34.66 \%$ compared to $10 \%$ in normal weight women with the p value $<0.001 \%$. The indication for NICU admission was preterm, baby of GDM mother and meconium aspiration syndrome.

\section{Conclusion}

With a sedentary life style, more in house working pattern and altered food habits, there is an increased tendency for the population to move towards obesity. This is more so during pregnancy when most of the women tend to take more rest and eat different food stuffs to suit their need and taste. The general affluence also contributes to the increased incidence of obesity, particularly in pregnancy.

The higher incidence of pregnancy complications in obesity is well borne out by many studies and this study also correlates with most of the studies. The higher incidence of pregnancy complications like anemia, pre eclampsia and gestational diabetes are well known affections of obesity. There is also an increased incidence of operative delivery and attendant anesthetic complications. The third stage of labor is also fraught with complications in the obese women compared to their non obese sisters. The common third stage complications are PPH and retained placenta which could be life threatening.

Obese babies, even in the absence of GDM, have a higher requirement of NICU admission and perinatal complications. Though this study did not reveal any increase in perinatal mortality due to obesity, the higher incidence of NICU admission is well revealed. Similarly still birth rates are also marginally higher than in the non obese women. Hence it is imperative that the fight against obesity should start at the adolescent age itself when both the boys and girls tend to indulge in binge eating and in junk food. For those obese mothers, the need for restructuring their caloric intake and exercise without harming the pregnancy should be stressed. The need of the hour is a life style modification and eating habits.

\section{References}

[1]. American College of Obstetricians and Gynecologists: The role of the obstetrician-gynecologist in the assessment of and management of obesity. Committee Opinion No. 319, October 2005b

[2]. Bianco AT, Smilen SW, Davis Y, et al: Pregnancy outcome and weight gain recommendations for the morbidly obese woman. ObstetGynecol 91:97, 1998 [PMID: 9464729]

[3]. Baeten JM, Bukusi EA, Lambe M. Pregnancy complications and outcomesamong overweight and obese nulliparous women. Am J Public Health 2001;

[4]. Cnattingius S, Bergstrom R, Lipworth L, et al: Prepregnancy weight and the risk of adverse pregnancy outcomes. N Engl J Med 338 : 147, 1998 [PMID: 9428815]

[5]. Ehrenberg HM, Mercer BM, Catalano PM: The influence of obesity and diabetes on the prevalence of macrosomia. Am J ObstetGynecol 191:964, 2004 [PMID: 15467573]

[6]. Gabbe SG: Gestational diabetes mellitus. N Engl J Med 315(1986) 1025

[7]. Lu GC, Rouse DJ, DuBard MA, et al: The effect of the increasing prevalence of maternal obesity on perinatal morbidity. Am J ObstetGynecol 185:845, 2001 [PMID: 11641663]

[8]. Lynch CM, Sexton DJ, Hession M, et al: Obesity and mode of delivery in primigravid and multigravid women. Am J Perinatol 25(3): 163,2008

[9]. O'Brien TE, Ray JG, Chan WS: Maternal body mass index and the risk of preeclampsia: A systematic overview. Epidemiology $14: 368,2003$

[10]. Poobalan AS, Aucott LS, Gurung T, et al: Obesity as an independent risk factor for elective and emergency caesarean delivery in nulliparous women - systematic review and meta-analysis of cohort studies. Obes Rev 10:28, 2009 [PMID: 19021871]

[11]. Sebire NJ, Jolly M, Harris JP, et al: Maternal obesity and pregnancy outcome: A study of 287,213 pregnancies in London. Int J ObesRelatMetabDisord 25:1175, 2001 [PMID: 11477502]

[12]. Stephansson O, Dickman PW, Johansson A, et al: Maternal weight, pregnancy weight gain, and the risk of antepartum stillbirth. Am J ObstetGynecol 184:463, 2001 [PMID: 11228504] 